\title{
Política Linguística e o ensino de Língua Portuguesa no contexto escolar
}

\author{
Language Policy and Portuguese Language teaching in the school context \\ Política Linguiística y la enseñanza del Lenguaje Portugués en el contexto escolar
}

Talita Aparecida da Guarda Alves

ORCID: https://orcid.org/0000-0003-4889-1116 Universidade Federal de Uberlândia, Brasil E-mail: talita.guarda@ifnmg.edu.br

\begin{abstract}
Resumo
O objetivo geral deste trabalho foi investigar as concepções dos professores sobre o ensino de língua materna e sua relação com a Política Linguística no contexto do Ensino Médio de uma cidade do Norte de Minas Gerais. Para tanto, a opção metodológica foi de caráter exploratório de natureza qualitativa e interpretativista. Para a coleta de dados, foram feitas entrevistas com quatro professores da rede pública e da rede particular de uma cidade do Norte de Minas Gerais. Refletimos, neste trabalho, sobre as representações do ensino de Língua Portuguesa e como este ensino vem acontecendo no contexto das escolas pesquisadas. A hipótese que guiou este trabalho pareceu se confirmar, ao menos no que se refere às instituições investigadas, uma vez que foi verificado que há uma ênfase maior ao ensino de língua focado na tradição gramatical, evidenciando a Língua-Padrão como a única correta, deixando de lado as demais variantes. No que se refere à Política Linguística, verificou-se que ainda falta uma Política Linguística consistente que abarque a realidade linguística do nosso país. O trabalho evidenciou a necessidade de este tema ser amplamente divulgado nas universidades, nos cursos de graduação e de pós-graduação, pois muitos professores ainda não possuem familiaridade com este assunto.
\end{abstract}

Palavras-chave: Políticas linguísticas; Ensino; Língua portuguesa.

\begin{abstract}
The aim of this work was to investigate the teachers' conceptions about first language teaching and its relation with Language Policies in High school in the context in a city in the North of Minas Gerais. Therefore, we chose a qualitative and interpretative exploratory research method. For data collection, interviews were conducted with four teachers from a public school and a private school of a city in the North of Minas Gerais. On this work we discuss Brazilian Portuguese language teaching representations and how this teaching occurs in the context of the investigated schools. The hypothesis that guided this work seemed to be confirmed, at least regarding the institutions investigated, since it was verified that there is a greater emphasis on language teaching focused on the grammatical tradition, establishing the Standard Language as the only correct one, putting aside other variants. As far as Language Policy is concerned, there has been a lack of consistent Language Policies that encompasses the linguistic reality of our country. The work evidenced the need for this theme to be widely disseminated in universities, undergraduate and postgraduate courses, since many teachers are not yet familiar with this subject.
\end{abstract}

Keywords: Language policies; Teaching; Brazilian portuguese language.

\section{Resumen}

El objetivo general de este trabajo fue investigar las concepciones de los docentes sobre la educación de la lengua materna y su relación con la Política Lingüística en el contexto de la escuela secundaria en una ciudad del norte de Minas Gerais. Por tanto, la opción metodológica fue de carácter exploratorio, cualitativo e interpretativo. Para la recolección de datos, se realizaron entrevistas a cuatro profesores de escuelas públicas y privadas de una ciudad del norte de Minas Gerais. En este trabajo, reflexionamos sobre las representaciones de la educación de la lengua portuguesa y cómo esta educación ha ido sucediendo en el contexto de las escuelas investigadas. La hipótesis que orientó este trabajo pareció confirmarse, al menos en lo que respecta a las instituciones investigadas, ya que se verificó que existe un mayor énfasis en la educación de lenguas centrada en la tradición gramatical, evidenciando el Lenguaje Estándar como el único correcto, dejando aparte de las otras variantes. En cuanto a la Política Lingüística, se constató que aún falta una Política Lingüística coherente que abarque la realidad linguiística de nuestro país. El trabajo destacó la necesidad de que este tema tenga una amplia difusión en las universidades, en los cursos de pregrado y posgrado, ya que muchos profesores aún no están familiarizados con este tema.

Palabras clave: Políticas Lingüísticas; Docencia; Lengua Portuguesa. 


\section{Introdução}

O ensino de línguas no Brasil, em especial o de Língua Portuguesa, tem sido um desafio para os professores, uma vez que os alunos estudam essa disciplina do Ensino Fundamental até o final do Ensino Médio e, mesmo assim, grande parte deles não aprende, nem desenvolve as competências necessárias para a leitura, a compreensão e a produção de textos, tanto escritos, quanto orais, de forma satisfatória. Nesse sentido, o objetivo do presente artigo consistiu em investigar as concepções de professores sobre o ensino de língua materna e sua relação com a Política Linguística, no contexto escolar de uma cidade do Norte de Minas Gerais.

O interesse por falar da relação entre ensino de língua materna e Política Linguística se deu pelo fato de que existem muitos estudos sobre Política Linguística ligados ao ensino de língua estrangeira, como a língua inglesa, mas poucos estudos que tratam de Política Linguística e o ensino de português, no Brasil. Esse interesse pelas línguas estrangeiras pode ser explicado, pelo menos em parte, por questões de ordem política.

Pode-se afirmar que, até recentemente, o tema Política Linguística não era conhecido de grande parcela de estudiosos da pesquisa linguística no Brasil, ao menos não como é discutida por alguns pesquisadores, como Rajagopalan (2003), Fiorin (2002), Correa (2009, 2010 e 2014), Nicolaides et al. (2013), dentre outros. Por esta razão, é importante que se façam pesquisas a respeito deste tema, na tentativa de sanar as lacunas existentes nessa área tão relevante da Linguística, especialmente no que se refere ao ensino da Língua Portuguesa, no contexto da escola regular no Brasil. Acreditamos que a união de vários trabalhos sobre o mesmo tema poderia favorecer a produção dos saberes deste campo de estudo e a compreensão do funcionamento das práticas de Política Linguística em andamento na sociedade brasileira contemporânea.

As pesquisas de estudiosos como Rajagopalan (2003, 2013 e 2014) e Calvet (2002 e 2007) são extremamente relevantes para a consolidação e o crescimento dessa área. Vale salientar que, segundo Calvet (2002), há mais de uma definição para o termo Política Linguística: a primeira discute Política Linguística como um conjunto de escolhas conscientes referentes às relações entre língua(s) e vida social; já a segunda, salienta o planejamento linguístico, a implementação prática de uma Política Linguística. A Política Linguística, tal como é entendida aqui, pode-se dizer, está ligada às decisões políticas que estão relacionadas a ações que estão sendo tomadas pela escola conscientemente para a efetivação mais bem sucedida do ensino de Língua Portuguesa.

Tentamos, na presente pesquisa, responder às seguintes questões: Quais as representações sobre a Língua Portuguesa construídas por professores do Ensino Médio, no contexto de ensino de escolas pública e particular?; Quais os possíveis impactos dessas representações no contexto de ensino de Língua Portuguesa?; O que pode ser percebido em relação à Política Linguística adotada para o ensino de Língua Portuguesa, no âmbito da escola regular, no contexto investigado?.

Consideramos como contexto de estudo a disciplina "Língua Portuguesa", ofertada no âmbito de quatro escolas, sendo uma municipal, uma estadual, uma federal e uma particular, de Ensino Fundamental e Médio, de uma cidade do Norte de Minas Gerais. A escolha dessas escolas, como locus de pesquisa, se deveu ao fato de tentarmos contrastar a realidade vivenciada, em relação ao tema pesquisado, nos diversos contextos das escolas da rede regular de ensino.

Para tanto, os dados foram produzidos a partir da realização de entrevistas semiestruturadas, com quatro professores de Língua Portuguesa, que lecionam no Ensino Fundamental e Médio, atuam em escolas públicas e particular, no Norte de Minas Gerais.

O artigo está organizado em duas seções, além desta introdução. A primeira seção trata dos procedimentos metodológicos. A segunda seção, dos Resultados e Discussão e, por fim, apresentamos as Considerações Finais. 


\section{Metodologia}

O objetivo deste artigo consistiu em investigar as concepções de professores sobre o ensino de língua materna e sua relação com a Política Linguística, no contexto escolar de uma cidade do Norte de Minas Gerais.

A pesquisa foi fundamentada em uma abordagem de caráter exploratório de natureza qualitativa e interpretativista. Segundo Minayo (1994) "a pesquisa qualitativa responde questões muito particulares, ela se preocupa com a realidade, com significados.” (p.21). Já para André (1983) a pesquisa qualitativa pretende apreender o caráter multidimensional dos fenômenos em sua manifestação natural, apreender, também, os diferentes significados de uma experiência vivida, auxiliando a compreensão do indivíduo no seu contexto. Para podermos analisar criticamente o problema em questão e produzirmos conhecimentos a esse respeito, fizemos estudo bibliográfico como passo inicial, em seguida a pesquisa de campo. Lima (2004) esclarece que a pesquisa de campo "pressupõe apreensão dos fatos/variáveis investigados, exatamente onde, quando e como ocorrem. Nessas circunstâncias, o pesquisador deve definir o que e como irá apreender, considerando as especificidades do que está investigando.” (p. 51).

Esta pesquisa foi realizada em quatro escolas, sendo uma municipal, uma estadual, uma federal e uma particular, de Ensino Fundamental e Médio, de uma cidade do Norte de Minas Gerais. A escolha dessas escolas, como locus de pesquisa, se deveu pelo fato de tentarmos contrastar a realidade vivenciada, em relação ao tema pesquisado, nos diversos contextos das escolas da rede regular de ensino. Por questões de sigilo, referiremo-nos às escolas, como Escola A, Escola B, Escola C e Escola D. E aos participantes como, professor 1 igual a P1, professor 2, como P2 e assim sucessivamente.

Os participantes da pesquisa foram quatro Professores de Língua Portuguesa, que lecionam no Ensino Fundamental e Médio, e atuam em escolas públicas e particular, no Norte de Minas Gerais. Os professores selecionados foram, somente, os que aceitaram participar da presente pesquisa.

Foram investigadas questões inerentes ao processo de ensino de língua materna e sua relação com a Política Linguística no Brasil. A escolha desses professores como participantes da pesquisa foi motivada pelo fato de eles terem aceitado participar da pesquisa e estarem disponíveis, no momento, em que a pesquisa ia acontecer. Ressaltamos que nosso projeto de pesquisa foi, inicialmente, submetido e aprovado pelo Comitê de Ética da Universidade Federal de Uberlândia.

Para a dissertação que deu origem a este artigo (Guarda, 2017), a entrevista foi feita de forma despadronizada [semiestruturada]. Segundo Minayo (1994) a entrevista "é uma conversa a dois, feita por iniciativa do entrevistador, destinada a fornecer informações pertinentes a um objeto de pesquisa." (p. 67). As entrevistas semiestruturadas foram feitas com cada participante separadamente, gravadas em áudio e, posteriormente, transcritas para serem feitas as análises.

O procedimento metodológico envolveu levantamento bibliográfico para entender as Políticas Linguísticas que estão atualmente em vigor no ensino de Língua Portuguesa no Brasil. Os professores foram selecionados por trabalharem em diferentes esferas: contexto público estadual, municipal e federal e contexto particular. As esferas são diferentes, pois leva-se em consideração os dois contextos em que ocorre o processo de aprendizagem de Língua Portuguesa: o público e o particular.

\section{Resultados e Discussão}

\subsection{As representações em jogo}

O objetivo desta seção é apresentar a análise e a discussão dos dados da pesquisa, que busca responder as três questões que norteiam este trabalho, tal como descrito abaixo. Analisamos, então, as representações sobre a Língua Portuguesa que estão em jogo no contexto de ensino das escolas.

Assim, tentamos responder às seguintes questões de pesquisa: 1) Quais são as representações sobre a Língua Portuguesa que estão em jogo no contexto de ensino?; 2) Quais os possíveis impactos dessas representações no contexto de 
ensino de Língua Portuguesa?; 3) O que pode ser percebido em relação à Política Linguística adotada para o ensino de Língua Portuguesa, no âmbito da escola regular, no contexto investigado?

Para tanto, utilizaremos, como subsídio, as respostas dadas às entrevistas direcionadas aos professores de Língua Portuguesa, participantes da pesquisa, que atuam nas redes públicas e privada.

O ensino de Língua Portuguesa no Brasil, por um longo período de tempo, consistia em explicitar os mecanismos de funcionamento da língua e em métodos de codificação e decodificação da língua, no entanto, com o passar do tempo, uma nova concepção de ensino surge, dando maior ênfase a outros aspectos do ensino da língua[gem], com objetivos mais amplos, tais como: a adequação de registros da língua nas mais diversas situações discursivas; o domínio da norma culta e da modalidade escrita da língua; o respeito às variantes linguísticas e o ensino da língua em uma perspectiva crítica.

Iniciaremos as discussões tentando responder à primeira pergunta de pesquisa, quais as representações sobre a Língua portuguesa estão em jogo no contexto de ensino?

Quando perguntamos aos professores o que eles achavam sobre a importância do ensino de Língua Portuguesa, P1 nos responde o seguinte:

\section{Excerto 01}

P1: Acredito que a importância do ensino de Língua Portuguesa seja preparar os estudantes para ter amplo domínio de leitura e escrita na norma culta da lingua portuguesa e conhecer as variedades linguísticas. E nosso papel, enquanto professores, é apresentar a língua como um universo próximo e acessivel, além de um instrumento universal e essencial ao ser humano para se comunicar. (P1, entrevista).

Verificamos, através dos dizeres de P1, que ele sabe da importância do ensino da língua e entende que seu objetivo "seja preparar os estudantes para ter amplo domínio de leitura e escrita na norma culta da Língua Portuguesa e conhecer as variedades linguísticas". O professor cita a norma culta porque percebe que essa variante linguística é a que vai ser cobrada dos alunos na sociedade; se eles não tiverem o acesso a essa norma, a escola não terá cumprido, de fato, seu compromisso. Há um abismo, criado pela própria sociedade, entre aqueles que falam e os que não falam de acordo com a norma culta, e quem não fala de acordo com essa variante da língua tem sua possibilidade de ascensão social reduzida. Por isso, segundo P1, é papel da escola fornecer condições para que o aluno tenha acesso a essa norma de maior prestígio social.

O ensino dessa variante da língua nas escolas é importante, pois é um direito do aluno como cidadão ter acesso à norma culta da língua, já que é esta a modalidade de prestígio que propiciará ao aluno a possibilidade de ascensão social e funcional, por ser essa modalidade exigida em todas as esferas de nossa sociedade. Fiad e Carbonari (1985) destacam que é uma função democrática e antielitista proporcionar aos alunos o acesso à modalidade linguística escrita e oral que é utilizada pelos grupos de prestígio da sociedade.

P1 também trás a questão das "variedades linguísticas", que são, na verdade, as variantes linguísticas. Ele destaca a importância de se trabalhar, em sala de aula, essas variantes, pois percebe a necessidade de o professor aproximar-se do universo do qual o aluno faz parte. Como observa Corrêa (2009), são necessárias reflexões sobre uma política de ensino de língua que a reconheça em toda sua multiplicidade, que a perceba com todo o seu caráter heterogêneo e multifacetado, que abarca o homem enquanto ser social que traz consigo todas as características da sociedade, como os fatores políticos, culturais, econômicos e ideológicos.

De acordo com os dizeres de P1, convém destacar a importância desta disciplina, uma vez que um de seus papéis é o de "preparar os estudantes para ter amplo domínio de leitura e escrita na norma culta da Língua Portuguesa e conhecer as 
variedades linguísticas". A partir dos dizeres de P1, percebemos que há, então, uma representação do papel do professor enquanto aquele que vai propiciar condições para que o aluno aprenda a língua.

P1 ressalta que "nosso papel, enquanto professores é apresentar a língua como um universo próximo e acessível", o que significa dizer que não se deve apresentar a língua como algo que está distante do aluno, mas como algo que esteja próximo dele e acessível a ele. Parece-nos que o professor tem uma visão próxima daquilo que Possenti (1996) argumenta em seu livro "Por que [não] ensinar gramática na escola". O autor tece uma crítica à forma como a Língua Portuguesa está sendo ensinada. Segundo ele, há um ensino a partir de explicitação enorme de regras e uma nomenclatura que o aluno não vê como parte daquilo que o constitui em termos linguísticos. Esta forma de abordar o ensino de Língua Portuguesa deixa o acesso à norma culta mais distante ainda dos alunos. $\mathrm{O}$ autor não está sugerindo, com isto, que a gramática não deva ser ensinada na escola, mas que deva ser abordada de outra forma, mais eficiente, de forma a fazer mais sentido para os alunos. Em seus dizeres, P1 menciona exatamente esta proximidade, que pode tornar o ensino mais acessível e próximo ao aluno.

Por outro lado, aparece na fala de P1, uma concepção, que é compartilhada pela maioria dos professores, a de língua como instrumento. Mas o que há de problemático nisso? A nosso ver, enxergar a língua como instrumento é vê-la como algo que se encontra fora do sujeito e não como parte constitutiva do sujeito; é como se a língua fosse um instrumento sobre o qual esse sujeito teria total controle, mas não é isto que acontece com a língua, pois não temos esse controle todo sobre ela. Como mostram os estudiosos da psicanálise, Lacan (1988) e Freud (1980), mesmo que façamos escolhas no plano do consciente, muita coisa escapa ao sujeito e a língua acaba "falando o sujeito", ao invés de o sujeito falar a língua. É a partir dos posicionamentos que o sujeito faz, por meio da linguagem, que se percebem suas inscrições ideológicas, seus preconceitos, etc.

Contudo, não podemos cobrar do professor, no caso, o participante da pesquisa, uma visão diferente porque isto está na base de formação dos professores, de modo geral, mas podemos propiciar discussões a respeito. Encarar a língua não como instrumento, mas como algo constitutivo do sujeito, como uma instância política, por exemplo, através da qual o sujeito vai agir sobre o mundo, não costuma fazer parte das discussões propiciadas nos cursos de formação docente. Se P1 não tem essa visão, ele apresenta a concepção de que ensinar língua não é ensinar uma nomenclatura complicada.

Veremos, no excerto 2, também relativo à primeira pergunta, que, para P3, o tipo de representação que está em jogo é a importância social do ensino de língua:

\section{Excerto 02}

P3: O ensino de Língua Portuguesa tem uma importância social muito grande. Garante a participação da pessoa na vida cidadã, na leitura e interpretação da realidade, na capacidade de articular os conhecimentos perpassados pela linguagem. Além disso, o ensino dessa disciplina pode levar o aluno a um entendimento maior dos discursos e das políticas que estão imbricados no dizer e no modo do dizer. (P3, entrevista).

P3 ressalta a importância social que o ensino de Língua Portuguesa tem e a ideia de que o professor é peça fundamental nesse processo, uma vez que precisa ser um agente facilitador do processo constante de formação cidadã. $\mathrm{O}$ objetivo do professor, segundo ele, deve estar voltado para preparar o estudante para a utilização dos conhecimentos adquiridos na escola a seu favor na vida diária. Esta ideia é explicitada no artigo 22, da Lei de Diretrizes e Bases da Educação Brasileira ( $n^{\circ}$ 9394/96), que ressalta que a educação básica tem por objetivo "desenvolver o educando, assegurar-lhe a formação indispensável para o exercício da cidadania e fornecer-lhe meios para progredir no trabalho e em estudos posteriores." (Brasil, 1996, p.8).

Nesse sentido, Moita Lopes (1996, p. 182) ressalta a importância de o professor despertar no aluno a consciência crítica de interação social, pois o aluno ocupa diversos papéis sociais que carregam marcas que determinam os papéis 
interacionais que ocupamos nas relações de poder. Logo, aprender uma língua[gem] significa aprender a participar da vida em sociedade. Estas noções estão presentes na fala de P3, quando afirma que o conhecimento da língua possibilita “a participação da pessoa na vida cidadã, na leitura e interpretação da realidade, na capacidade de articular os conhecimentos perpassados pela linguagem". Os dizeres de P3 vão ao encontro do que está proposto nos Parâmetros Curriculares Nacionais (PCNs): “um projeto educacional comprometido com a democratização social e cultural atribui à escola a função e a responsabilidade de garantir a todos os seus alunos o acesso a saberes linguísticos necessários para o exercício da cidadania” (Brasil, 2000 p. 8).

P3 acredita que o ensino de Língua Portuguesa pode "levar o aluno a um entendimento maior dos discursos e das políticas que estão subentendidos no dizer e no modo do dizer”. Dessa forma, podemos inferir a importância social que o professor atribui ao ensino de Língua Portuguesa, uma vez que é a partir do conhecimento ensinado em sala de aula que o aluno aprimora sua capacidade de entender e interpretar o mundo que o cerca. Ele tem razão, uma vez que, se o professor ensinar o aluno a ler de forma acrítica, ler apenas de forma decodificada, não entender o que está nas entrelinhas, não ultrapassar a barreira do texto e cair na dimensão discursiva, ele estará instrumentalizando o aluno a não ter criticidade, levando-o a acreditar em tudo o que lê.

Ensinar leitura, não depende, necessariamente, de ensinamento de todas as regras gramaticais, mas não se pode descartá-la totalmente, uma vez que alguns de seus aspectos devem ser evidenciados. A gramática não deve ser ensinada pela gramática por si só, deve-se contextualizá-la, deve-se ter um propósito ao ensiná-la, trazer quais os pontos gramaticais são importantes de o aluno conhecer para se tornar um leitor proficiente, para que ele melhore seu desempenho na leitura de textos.

Já para produção de texto é necessário o levantamento de diversos pontos da gramática, tais como regras de segmentação, construção de períodos compostos, as relativas, concordância, regência, dentre outras regras. Por isso a importância de o professor estar atento a esses aspectos sobre leitura e produção de texto para poder propiciar que o ensino de Língua Portuguesa, de fato, seja um diferencial na vida do aluno. Dessa forma, Silva e Dias (2020) ressaltam "a ideia da importância do estudo por meio de textos para a formação da competência linguística, pois estes correspondem ao conjunto de palavras/frases que possuem sentido completo, oportunizando aos interlocutores a compreensão e interpretação ocasionando, como resultado, a conversação.” (p. 06).

Veremos a seguir, os dizeres de P4, que deixam flagrar a representação que ela tem sobre ensino de Língua Portuguesa; a de um ensino pautado no "conhecimento da língua".

\section{$\underline{\text { Excerto } 03}$}

P4: Primeiramente destacar a importância fundamental de se conhecer a nossa língua materna, a língua que usamos diariamente no nosso cotidiano, depois destacar todos os aspectos que esse ensino nos favorece: melhor utilização da mesma, melhor interpretação de texto, maior criticidade. (P4, entrevista).

O que se percebe nos dizeres de P4 é que não fica claro o que é "conhecer a língua materna". Quando ele diz: “destacar a importância fundamental de se conhecer a nossa língua materna, a língua que usamos diariamente no nosso cotidiano...” podemos inferir que ele esteja se referindo tanto à explicitação das normas e das regras, quanto ao dialeto oral que é usado em contextos informais, bem como, o dialeto padrão escolarizado da Língua Portuguesa de acordo com a norma culta, especialmente na modalidade escrita.

Por outro lado, quando P4 menciona “depois destacar todos os aspectos que esse ensino nos favorece...”, infere-se que ele esteja se referindo ao ensino da norma culta e que "conhecer a língua", para ele, seja conhecimento da norma. Para o professor, a "língua do cotidiano" parece estar ligada à língua falada na comunidade ou em casa. Para ele, é através desse ensino da norma culta que temos a possibilidade de "melhor interpretação de texto e usar a língua com maior criticidade e 
eficiência”. Percebemos a semelhança dos dizeres de P4 com os de P3, ambas ressaltam a importância do ensino de Língua Portuguesa, uma vez que este pode permitir que o aluno aprenda a ser crítico e saiba se posicionar em diferentes situações e contextos a que estiver exposto na vida em sociedade, e, como consequência disso, compreender o funcionamento da língua dentro do texto e através da leitura, torna-se, para P4 um ponto importante.

A escola sabe que é seu papel dar o acesso à norma culta, na modalidade escrita e na modalidade oral, mas, ao mesmo tempo, não é consenso entre os professores de Língua Portuguesa como fazer isto. Então, o ensino acaba sendo falho por excesso de sistematização de normas, regras e nomenclaturas que não são sinônimos de efetivamente saber usar a língua nas modalidades oral e escrita com funcionalidade, criatividade e proficiência.

Não questionamos o fato de ser papel da escola, propiciar aos alunos o acesso à norma culta e ao ensino do dialeto padrão escolarizado. O que se problematiza aqui é a ideia, sustentada pela escola, de que quem não conhece a norma culta não sabe português. Nesse sentido, é possível dizer que ainda se observa a postura da escola, na figura dos professores de Língua Portuguesa, de não considerarem legítimas outras variantes da língua portuguesa. Contudo, deve-se distinguir a modalidade oral da língua, em circunstâncias de comunicação do dia a dia, pois o aluno sabe usar perfeitamente a língua: comunica-se, interage e é fluente. Porém, quando se trata de redação, na modalidade escrita da língua, muitos apresentam dificuldades, pois não conseguem expressar suas ideias. Mesmo na modalidade oral, quando têm que desenvolver gêneros discursivos mais formais tais dificuldades aparecem.

Nessa mesma perspectiva, Possenti (1996) reitera que "o domínio efetivo e ativo de uma língua dispensa o domínio de uma metalinguagem técnica". (p. 53). Ele questiona o ensino das normas que é feito por meio de uma nomenclatura difícil que é estranha ao universo do aluno. "É perfeitamente possível aprender uma língua sem conhecer os termos técnicos com os quais ela é analisada". (Possenti, 1996, p.53).

Passaremos, agora, a analisar as respostas dadas à questão: "Como você descreveria o cenário do ensino de Língua Portuguesa no Brasil?" No excerto abaixo, veremos os dizeres de P1.

\section{Excerto 04}

P1: A educação no Brasil apresenta muitos desafios, e com o ensino de Língua Portuguesa não é diferente, os professores competem com as tecnologias (celular, tablet, etc), os alunos estão cada vez mais desinteressados, as aulas de português, muitas vezes, ficam restritas a textos e ao estudo de gramática, o que torna as aulas cansativas. Outras vezes, ainda que o professor use recursos tecnológicos, os alunos não se interessam. O cenário é triste e precisa urgentemente de mudanças, tanto nas escolas quanto no próprio sistema educacional. (P1, entrevista).

Percebe-se, através da fala de P1, que, o ensino da língua portuguesa no Brasil enfrenta problemas. Para o professor, a sociedade não é mais a mesma, tendo em vista as mudanças principalmente na área da tecnologia, da informação e da comunicação. Os alunos utilizam as tecnologias em sala de aula, na escola, em casa e nas ruas, e isto já faz parte da rotina de muitos estudantes. Para ele, as tecnologias existentes e presentes no dia a dia do aluno chamam mais sua atenção do que as aulas. O que se percebe é que os professores não estão sabendo como fazer uso da tecnologia de forma a atrair a atenção do aluno, uma vez que, nas aulas de Língua Portuguesa, utilizam métodos antigos e pouco atraentes aos alunos. Ou, muitas vezes, utilizam tecnologias para revestir de novo o que é velho. A forma de abordar o texto é a mesma, a forma de ensinar a gramática é a mesma.

P1, ainda, destaca que os alunos apresentam desinteresse em sala de aula, pois há um trabalho contínuo com a gramática e com o texto. Isto nos leva a pensar em um ensino descontextualizado e desconectado da realidade do aluno, o que contribui para seu desinteresse na disciplina de Língua Portuguesa. Desta maneira, diante desse cenário, alunos e professores ficam desmotivados e isto leva a aulas que pouco proporcionam a construção do conhecimento. 
O que se pode inferir dos dizeres de P1 é que muitos professores veem as tecnologias como algo negativo, no entanto, o uso da tecnologia na educação pode favorecer um ensino mais completo e de qualidade, pois o aluno pode ter à sua disposição, ferramentas que podem ajudá-lo a ter acesso a informações de maneira muito rápida e precisa, ter acesso a softwares educativos que permitem sua interação com o conhecimento e que podem ajudá-lo a desenvolver mais autonomia, etc. Tudo isto pode levar a um ensino mais concreto, por esta razão, a escola não deveria encarar o uso das tecnologias como algo ruim para o ensino; deveria utilizá-la a seu favor.

Diante do exposto por P1, a representação que se percebe do ensino de Língua Portuguesa é a de um ensino que está ficando obsoleto, tanto por parte da postura da escola, quanto por parte das políticas educacionais aplicadas ao ensino. Isto é percebido em sua fala: "O cenário é triste e precisa urgentemente de mudanças, tanto nas escolas quanto no próprio sistema educacional". (P1, entrevista).

Contudo, mudanças já começam a aparecer com a Base Nacional Comum Curricular (BNCC). Nela estão descritas sete competências específicas de linguagens e suas tecnologias para o Ensino Médio, que objetivam orientar as práticas de ensino de Língua Portuguesa, a fim de permitir que os alunos "desenvolvam competências e habilidades que lhes possibilitem mobilizar e articular conhecimentos desses componentes simultaneamente a dimensões socioemocionais, em situações de aprendizagem que lhes sejam significativas e relevantes para sua formação integral.” (Brasil, 2017, p. 483).

No excerto abaixo, veremos a resposta dada por P4 para a mesma questão. Em sua fala, ele destaca, também, o ensino da gramática em nossas escolas.

\section{$\underline{\text { Excerto } 05}$}

P4: Eu percebo que embora haja toda uma política de ensino da língua, um programa de trabalho a ser seguido, [o ensino da Língua Portuguesa] é algo muito complexo ainda, porque cada professor utiliza uma abordagem diferente. Alguns muito presos à gramática tradicional, outros com uma vertente mais funcional. Então, é muito difícil, porque a abordagem normativa ainda é muito forte e grande parte dos profissionais prefere segui-la, talvez por comodismo, deixando de abordar as demais variantes da língua. (P4, entrevista).

Percebemos, através do excerto cinco, que existem políticas de ensino da língua que orientam o ensino dessa Língua Portuguesa de modo geral, tais como o Currículo Básico Comum (CBC), as matrizes de língua portuguesa; e também, a Lei ${ }^{\circ}$ 9.394, de 20 de dezembro de 1996, passa a vigorar acrescida da Base Nacional Comum Curricular, que definirá os direitos e os objetivos de aprendizagem do ensino médio, conforme diretrizes do Conselho Nacional de Educação, na área de linguagens e suas tecnologias.

No entanto, P4 afirma que cada professor utiliza uma abordagem de ensino diferente. Isto é importante porque o professor não fica preso às regras e diretrizes, mas, por outro lado, na visão de P4, isto acaba sendo ruim porque o professor não segue uma única direção. "[o ensino da Língua Portuguesa] é algo muito complexo ainda, porque cada professor utiliza uma abordagem diferente". Este é um ponto positivo, pois a escola não pode engessar a prática do professor de tal maneira a exigir que todos usem a mesma metodologia. Por isso, a abordagem é algo importante, por exemplo, o professor pode abordar a leitura em sala de aula de diversas maneiras, no entanto, deve abordá-la como prática social e prática de interação, que vai além da simples decodificação do texto. Machado et al. (2020) ressaltam essa ideia ao afirmar "a importância da leitura como o espaço em que ela tenha função social, que se manifeste nas diferentes opiniões, mexendo nas estruturas, reinventando jeitos de agir e de viver em harmonia e de forma humanizada." (p. 04).

$\mathrm{O}$ que nos chama atenção nos dizeres de P4 é o fato de ele fazer uma crítica e ver como problema os professores focarem em abordagens diferentes em sala de aula, "porque cada professor utiliza uma abordagem diferente". Isto, a nosso 
ver, é problemático, uma vez que o professor tem a liberdade de trabalhar o conteúdo utilizando a abordagem que melhor atender ao momento vivido em sala de aula.

Outro aspecto destacado pelo professor é o fato de alguns professores ficarem presos à gramática tradicional, que inferimos se referir ao ensino da gramática normativa, ou o ensino da gramática de forma descontextualizada. Por outro lado, há os professores que se utilizam da "vertente funcional" para ensinar a língua. Vertente que mostra as funções de cada escolha linguística no texto, que envolva a realidade social do aluno em sua prática e mostra os aspectos sociais e históricos que são inerentes à linguagem. P4 deixa implícita uma crítica ao ensino tradicional, talvez pela utilização de técnicas e métodos de ensino que ela julga serem ultrapassados.

Verificamos por meio da fala de P4, que a Política Linguística praticada pela escola, ainda hoje, é ligada a um ensino de língua voltado para explicitação de normas gramaticais, numa abordagem estruturalista. A representação de língua e de ensino de língua apresentada por muitos professores, de que ensinar língua é ensinar gramática, leva a uma Política Linguística da Língua Portuguesa no contexto da escola que está se mostrando muito problemática. Jabur (2014, p. 39) destaca que no Ensino Médio, o ensino de Língua Portuguesa é fortemente marcado por um trabalho com ortografia, morfologia, sintaxe, enfim aspectos da gramática normativa, e, quando se trabalha com produção e compreensão de textos, a escola o faz de maneira descontextualizada através de questionários, muitas vezes, iguais para todo tipo de texto. Travaglia (1998) ratifica a fala de Jabur (2014), afirmando que

[o] ensino de gramática em nossas escolas têm sido primordialmente prescritivo, apegando-se a regras de caráter normativo que como vimos, são estabelecidas de acordo com a tradição literária clássica, da qual é tirada a maioria dos exemplos. Tais regras e exemplos são repetidos anos a fio como formas "corretas" e boas a serem imitadas na expressão do pensamento. (p. 101).

Contudo, sabemos da importância do ensino da variante padrão da língua. O que se discute, aqui, é um ensino de língua materna voltado apenas para o ensino da modalidade padrão da língua, em sua versão escrita. Com certeza, essa é uma das finalidades do ensino da língua, visto que a variante não padrão o aluno já traz consigo. Contudo, é a maneira como tal prática é realizada em sala de aula que necessita ser rediscutida. Ainda segundo Travaglia (1998), há, na escola, uma ausência de atividades que envolvem produção e compreensão de textos, isso é negativo, uma vez que o estudo desses aspectos poderia contribuir para o desenvolvimento de competências linguísticas e comunicativas.

Respondendo à segunda questão de pesquisa, quais os possíveis impactos dessas representações no contexto de ensino de Língua Portuguesa? Percebemos que uma das representações apresentadas pelos professores sobre o ensino de Língua Portuguesa é a de que saber a Língua Portuguesa é saber a língua do padrão escolarizado, ou seja, quem não sabe as regras gramaticais, de acordo com as normas prescritivas, não sabe a Língua Portuguesa. O impacto dessa representação pode ser o fato de que a escola irá prestigiar apenas a variante culta da língua, desprezar as outras variantes e reforçar a estigmatização de variantes que não são consideradas legítimas pela sociedade e pela própria escola.

Dessa forma, fica mais acentuado o preconceito linguístico presentes na escola e na sociedade, de modo geral. Contudo, como salientado anteriormente, sabemos da importância de a escola ensinar a variante culta da língua, tanto em sua modalidade oral, quanto escrita, uma vez que esta possibilita ao aluno ascender socialmente e funcionalmente; ter um melhor emprego; ser um cidadão crítico, que sabe expor sua opinião, ponto de vista; tem a possibilidade de interpretar melhor o texto e usar a língua com maior criticidade e eficiência. Fica evidente, então, o papel fundamental do professor como profissional que irá propiciar condições ao aluno para que ele aprenda a modalidade culta da língua, com um ensino que englobe a nomenclatura gramatical, de forma contextualizada. 


\subsection{O ensino de Língua Portuguesa e Política Linguística}

Abordaremos, agora, questões que estão diretamente relacionadas às Políticas Linguísticas. Iniciaremos com a questão que indaga o que os professores, participantes da pesquisa, entendem por Políticas Linguísticas.

Nos excertos abaixo, observaremos que P2 e P4 apresentaram convicção ao responder a questão sobre Política Linguística. A nosso ver, isso demonstrou que os professores estavam familiarizados com o tema, embora, tenham apresentado dificuldade para nos responder esta pergunta.

\section{Excerto 06}

P2: "Trata-se das decisões, discussões sobre as ações que devem ser tomadas no que diz respeito às línguas. Fazer o que for melhor para as línguas bem como o uso na sociedade." (P2, entrevista).

\section{Excerto 07}

P4: "Entendo como uma política de melhor abordagem do ensino da língua, uma espécie de direcionamento de ensino que seja mais eficaz." (P4, entrevista).

Os dizeres de P2, ao afirmar que Política Linguística "trata-se das decisões, discussões sobre as ações que devem ser tomadas no que diz respeito às línguas" vão ao encontro do que Calvet (2007) ressalta, quando afirma que há uma preocupação no que diz respeito à relação entre o poder e as línguas, ou, mais especificamente, com as grandes decisões políticas sobre as línguas e seus usos na sociedade. O autor salienta, ainda, que ações de Política Linguística definem quais línguas podem, ou não, ser usadas em determinados contextos, oficiais ou não; em como línguas são promovidas ou proibidas, a partir de ações, sobretudo do Estado sobre seus falantes [política de status]; em como línguas são instrumentalizadas para determinados usos [política de corpus].

No trecho que se segue, P2 apresenta um equívoco em sua fala, quando afirma que Política Linguística pode "fazer o que for melhor para as línguas, bem como o uso na sociedade.” Nem sempre isto acontece, pois, muitas vezes, a Política Linguística vem como uma imposição do Estado, tanto para o universo acadêmico, quanto para a sociedade, de modo geral. Ou seja, nem sempre o que está preconizado pela Política Linguística é o melhor para a língua. Isto vai de encontro com os dizeres de P4, quando esta fala que Política Linguística seria "uma política de melhor abordagem do ensino da língua, uma espécie de direcionamento de ensino que seja mais eficaz." Por isso, a nosso ver, é muito importante o engajamento e o conhecimento dos professores com relação a este tema, pois assim poderão cobrar e se manter inteirados sobre as políticas que estão em vigor em nosso país.

No excerto abaixo, em resposta à mesma questão, P3 afirma que as Políticas Linguísticas organizam o funcionamento da língua:

\section{Excerto 08}

P3: São as políticas que organizam o funcionamento do ensino de língua, e que, de certa forma, perpassam todas as decisões desse cenário, desde a escolha do livro didático, até como a disciplina é cobrada no ENEM e provas similares. São as políticas que determinam, por exemplo, foco menor no ensino da oralidade - capaz de formar pessoas para a manifestação consciente e crítica do seu pensamento. Ações e projetos que mapeiam as variedades linguísticas e as línguas faladas no Brasil. (P3, entrevista)

A partir dos dizeres de P3 a respeito do que ele entende por Política Linguística, notamos que ele define Políticas Linguísticas como o que determina as decisões que são tomadas em relação à determinada língua e ao seu ensino: "São as políticas que organizam o funcionamento do ensino de língua, e que, de certa forma, perpassam todas as decisões desse cenário.” Calvet (2007) salienta que não há como falar em Políticas Linguísticas sem falar em planejamento linguístico. Nesse 
sentido, a definição apresentada por P3 é exatamente o que faz o planejamento linguístico, ou seja, a implementação das políticas, das decisões sobre a língua, por meio de estratégias (políticas), como as políticas educacionais, com vistas a influenciar o comportamento dos sujeitos com relação ao aprendizado da língua. Isso vai ao encontro da proposta do Novo Ensino Médio, em que apresenta uma Base Nacional Comum Curricular (BNCC), ou seja, um conjunto de orientações que deverá nortear a [re]elaboração dos currículos de referência das escolas das redes públicas e privadas de ensino de todo o Brasil. (Brasil, 2017).

P3 sustenta, ainda, em sua fala, que as Políticas Linguísticas influenciam no uso das modalidades linguísticas utilizadas em sala de aula: "são as políticas que determinam, por exemplo, foco menor no ensino da oralidade." Infere-se pela fala de P3 que o trabalho com a escrita é importante, mas que o ensino da oralidade também é. P3 fala também de ações importantes relacionadas às Políticas Linguísticas, tais como "projetos que mapeiam as variedades linguísticas e as línguas faladas no Brasil.”

Em outra pergunta, questionamos aos professores como eles descreveriam as Políticas Linguísticas vigentes no Brasil hoje, qual sua importância e o que eles esperam delas. Na resposta de P1, ele afirma não ter conhecimento das Políticas Linguísticas vigentes no Brasil. Vejamos no excerto nove:

\section{Excerto 09}

P1: "Não tenho conhecimento sobre as Políticas Linguísticas vigentes no Brasil." (P1, entrevista).

Os dizeres de P1 deixam evidente sua falta de compreensão a respeito de Política Linguística. Isso mostra o quanto este tema, ainda hoje, não é discutido nem na universidade, nem na escola, uma vez que P1 se formou recentemente. Inferimos que P1 não soube discorrer sobre as Políticas Linguísticas vigentes no Brasil, mas tem ciência da existência de normas, leis e orientações inerentes ao ensino de línguas. Só não sabe que isto são Políticas Linguísticas. A nosso ver, ele diz que não sabe, talvez por medo de não corresponder às expectativas da pesquisadora, então, parece que P1 tenta se resguardar dizendo "não tenho conhecimento sobre as políticas linguísticas vigentes no Brasil".

Sendo assim, inferimos que P1 sabe que existem, no Brasil, diversas leis, normas e orientações que conduzem o ensino, de modo geral, e existem também as regulamentações referentes ao ensino de línguas, tanto da portuguesa como das estrangeiras. Determinadas normativas apresentam caráter explícito de Política Linguística, como a Lei de Diretrizes e Bases da Educação Brasileira, outras, implicitamente, buscam orientar o processo de ensino e aprendizagem de línguas e a elaboração dos currículos escolares. É este o caso dos Parâmetros Curriculares Nacionais (PCNs) e da Base Nacional Comum Curricular (BNCC). Veremos no excerto abaixo, os dizeres de P2:

\section{Excerto 10}

P2: Há vários momentos na história do Brasil onde se fala e busca promover as Políticas Linguísticas, uma vez que foram conquistados reconhecimentos das línguas brasileiras, valorização, utilização, mas há ainda muito a se fazer, principalmente, quanto à participação nas decisões que respeitam e promovam o direito às línguas. (P2, entrevista).

Há nos dizeres de P2, a afirmação de que "há vários momentos na história do Brasil onde se fala e busca promover as Políticas Linguísticas." No entanto, a utilização de Política Linguística como área é bem recente; até os anos de 2006, havia apenas na Universidade Federal de Santa Catarina, um programa de pós-graduação em linguística, que tinha uma linha de pesquisa em Política Linguística. Isto mostra que as discussões sobre este assunto não são tão antigas, ao menos no Brasil. Os 
estudos sobre Política Linguística nasceram por volta da década de 1960 e estão diretamente ligados à relação de língua e poder, ou, como afirma Calvet (2007), às grandes decisões políticas sobre as línguas e seus usos na sociedade.

P2 deixa claro em sua fala que "foram conquistados reconhecimentos das línguas brasileiras" isto nos parece um equívoco, pois, houve, historicamente, uma supressão de outras línguas faladas no Brasil e uma imposição do Português como língua oficial brasileira.

Nos dizeres de P2, há implícita, uma preocupação quanto à participação nas tomadas de decisões, "mas há ainda muito a se fazer, principalmente, quanto a participação nas decisões que respeitam e promovam o direito às línguas." Esse posicionamento de $\mathrm{P} 2$ é muito importante, pois mostra que o professor deve estar atento às decisões sobre Política Linguística que são, de certa forma, impostas pelo governo à sociedade. Monte Mór (2013, p.15) depreende que muitos professores não possuem intimidade com o tema Política Linguística. Isto é ruim, porque é necessário que o professor familiarize-se sobre os assuntos de Política Linguística para que ele não seja mero aplicador ou implementador das ações de Política Linguística, mas possa, verdadeiramente, participar das decisões e criação dessa política.

Ainda sobre a sexta pergunta, veremos abaixo a resposta que $\mathrm{P} 3$ apresenta.

\section{Excerto 11}

P3: "Primeiramente, eu espero que as políticas possam intervir no processo de formação de professores de Língua Portuguesa e na formação continuada desses profissionais. Que a elaboração de materiais contemplasse mais os aspectos regionais e que não fosse tão metropolizado, como é hoje. Espero que as políticas ampliem sua atuação e reforcem o valor da existência de todas as linguas faladas no Brasil”.

Em relação às políticas vigentes, destaco os documentos como os PCNs, as pesquisas que envolvem a criação de atlas linguístico e os trabalhos da Sociolinguística que têm divulgado as línguas faladas aqui e as variedades linguísticas. Ainda vale destacar os trabalhos de descrição das línguas indígenas aqui no Brasil. Avançamos, mas há muito o que fazer para ampliar o olhar científico sobre a diversidade linguística e a participação social”. (P3, entrevista).

Inicialmente, $\mathrm{P} 3$ toca em um assunto de grande relevância "eu espero que as políticas possam intervir no processo de formação de professores de Língua Portuguesa e na formação continuada desses profissionais." Falar de intervenção da Política Linguística na formação de professores de línguas leva-nos a pensar em uma formação de docentes críticos-reflexivos. Ou seja, profissionais que são capazes de refletir sobre os processos de ensino/aprendizagem de línguas. Além disso, com uma formação inicial ou continuada adequada é possível desenvolver no professor de línguas a competência linguísticocomunicativa, isto é, "a capacidade de uso da língua-alvo, envolvendo conhecimento sobre a sua estrutura e seu funcionamento enquanto código linguístico e social para produção e interpretação de sentidos." (Almeida, 1993, p. 20).

Outro ponto de grande relevância que P3 destaca é sobre a elaboração de material didático que se utiliza em sala de aula: "que a elaboração de materiais contemplasse mais os aspectos regionais e que não fosse tão metropolizado, como é hoje." Isto vai ao encontro das ideias de Monte Mór (2013, p.15) que ressalta ser muito importante para o planejamento docente levar em consideração as necessidades dos alunos, o contexto de ensino, numa visão que reinterpreta as sugestões ou orientações 'globais' ou 'nacionais' de maneira a contemplar o que é local". Conforme os dizeres de $\mathrm{P} 3$, se nos próprios materiais didáticos já fossem contemplados os fatores regionais, haveria maior facilidade na construção do conhecimento pelo aluno, uma vez que este estaria em contato com materiais que retratariam sua vivência. Em Brasil (2017), o parágrafo primeiro já aponta para a parte diversificada dos currículos, que deverá estar harmonizada à Base Nacional Comum Curricular e ser articulada a partir do contexto histórico, econômico, social, ambiental e cultural. 
Depreendemos dos dizeres de P3 uma preocupação de que as Políticas Linguísticas não fiquem alheias às diversas línguas existentes em nosso país "espero que as políticas ampliem sua atuação e reforcem o valor da existência de todas as línguas faladas no Brasil." Como se sabe, o Brasil é um país multilíngue, no entanto, há uma visão, a nosso ver, equivocada, de que, aqui, só se fala o português e este é tido como língua materna de todo brasileiro. Contudo, no Brasil, se fala as Línguas Portuguesa, Indígena, Estrangeiras, de Sinais e de Imigração. Sendo assim, as Políticas Linguísticas que hoje vigoram no país devem progredir, com o objetivo de reconhecer, valorizar e contemplar de maneira mais adequada as línguas maternas de todos os brasileiros; assim como devem reconhecer, também, que o Brasil é um país plurilinguístico e pluricultural. Não obstante, reconhecemos que a Língua Portuguesa é a língua que proporciona a comunicação de um extremo ao outro do Brasil, por isso, seu ensino é tão importante.

P3 menciona os Parâmetros Curriculares Nacionais (PCNs) como Política Linguística vigente no Brasil, como citado neste trabalho anteriormente, os PCNs se caracterizam por serem uma Política Linguística implícita, ou seja, servem como orientações aos docentes. "Em relação às políticas vigentes, destaco os documentos como os PCNs." (P3, entrevista). Ele menciona, ainda

as pesquisas que envolvem a criação de atlas linguístico e os trabalhos da Sociolinguística que têm divulgado as línguas faladas aqui e as variedades linguísticas. Ainda vale destacar os trabalhos de descrição das línguas indígenas aqui no Brasil. Avançamos, mas há muito o que fazer para ampliar o olhar científico sobre a diversidade linguística e a participação social. (P3, entrevista).

Os dizeres de P3 apresentam a diversidade linguística do Brasil e a Política Linguística do português vigente atualmente na escola. Dessa forma, fica claro em sua fala, a ênfase que dá aos estudos que envolvem as várias línguas faladas no Brasil e consequentemente as variantes linguísticas que estão presentes nas diversas regiões do país. Veremos agora, ainda sobre a mesma questão, os dizeres de P4. Ele aborda a diferença entre teoria e prática. Vejamos:

\section{$\underline{\text { Excerto } 12}$}

P4: As Políticas Linguísticas, teoricamente, são muito bem elaboradas e bem feitas, são fundamentais para um direcionamento comum de ensino, no entanto, existe uma discrepância grande entre a teoria e a prática. Acredito que para que funcionassem bem, seria preciso maior apoio do governo na educação. É preciso formar professores mais reflexivos para que levem para a sala de aula um ensino mais produtivo da língua. (P4, entrevista).

Pelos dizeres de P4, "as Políticas Linguísticas, teoricamente, são muito bem elaboradas e bem feitas, são fundamentais para um direcionamento comum de ensino, no entanto, existe uma discrepância grande entre a teoria e a prática". Depreendemos, deste depoimento, que ele elogia as Políticas Linguísticas vigentes no Brasil, salientando sua importância, uma vez que servem como um norte a ser seguido. No entanto, segundo P4, as teorias propostas pelos documentos oficiais vão de encontro com a prática realizada pelos professores. Sobre as Políticas Linguísticas, o professor ressalta "para que funcionassem bem, seria preciso maior apoio do governo na educação".

Sem dúvida nenhuma, é necessário o apoio e financiamento do governo na educação, são necessários investimentos em pesquisas e ações de Política Linguística. É preciso dar ênfase ao tema Política Linguística nas universidades, inseri-lo nas grades curriculares tanto de graduações, quanto de pós-graduações e, também, nos cursos de formação continuada. Só assim teremos professores com uma formação mais completa nessa área tão importante do conhecimento. P4, ainda fala da importância da formação docente, é "preciso formar professores mais reflexivos para que levem para a sala de aula um ensino mais produtivo da língua". Vemos em seus dizeres sua preocupação com a formação de professores mais reflexivos, mas o que 
seriam, para ela, professores reflexivos. A nosso ver, seria o professor que está em processo contínuo de formação, que reflita sobre o papel de ensinar.

Por fim, respondendo nossa última questão de pesquisa, o que pode ser percebido em relação à Política Linguística adotada para o ensino de Língua Portuguesa no âmbito das escolas regulares, no contexto investigado? Pudemos notar, de acordo com os dizeres dos participantes da pesquisa, que as Políticas Linguísticas norteiam o ensino da língua e influenciam diretamente na escolha dos conteúdos a serem ministrados em sala de aula, conforme citado por P3: "como a prova do ENEM não cobra a leitura de livros literários específicos, percebo os alunos e professores bem preocupados com a redação e postergando a leitura." De acordo com os dizeres de alguns professores, participantes da pesquisa, as Políticas Linguísticas ainda não funcionam bem porque a formação de professores, nessa área do conhecimento, ainda é falha. A nosso ver, apesar de haver ações de Política Linguística, a operação dela, acaba sendo filtrada pela formação de professores, pelas limitações da escola. Para os profissionais que buscam uma formação continuada, este problema é amenizado, pois podem ter um olhar mais crítico e reflexivo sobre o tema.

\section{Considerações Finais}

Iniciamos este trabalho apresentando a problemática de que o ensino de Língua Portuguesa no Brasil tem sido bastante desafiador para os professores, pois os alunos entram em contato com esta disciplina desde as séries iniciais do Ensino Fundamental até o final do Ensino Médio, contudo, muitos deles não apresentam proficiência nas habilidades e competências imprescindíveis para o desenvolvimento da leitura, da compreensão e da produção de textos, sejam escritos ou orais. Percebemos em nossa discussão, que esta situação é preocupante, uma vez que, os resultados apresentados pelos alunos em provas de nível nacional, tais como o ENEM, deixam evidente que, grande parcela dos alunos brasileiros, não compreende o que lê e não consegue estabelecer relações indispensáveis entre as diversas informações presentes no texto, não conseguindo, assim, elaborar um texto coeso e coerente.

Levando em consideração nosso objetivo, pudemos perceber muitas representações sobre ensino de Língua Portuguesa, construídas pelos professores que atuam no ensino regular. Representações essas que parecem nortear as condutas da escola e dos próprios professores em relação ao ensino dessa língua [português]. Tentamos também discutir os possíveis impactos dessas representações no contexto investigado e sua relação com as Políticas Linguísticas adotadas.

Verificamos que uma das representações que os participantes da pesquisa têm sobre o ensino de Língua Portuguesa é a de que o ensino deve ser pautado na norma culta, essa variante linguística prevalece nas escolas, apesar de alguns professores reconhecerem que seria importante que a escola mostrasse ao aluno também outras variantes da língua. Alguns professores reconhecem essas variantes como legítimas, mas admitem que a escola as negligenciam, privilegiando apenas aquela que considera a "correta".

Se por um lado essa atitude [por parte das escolas] traz pontos positivos, visto que propicia aos alunos o acesso à variante de mais prestígio social e cultural de nossa sociedade, ela deixa também uma enorme lacuna na formação dos alunos, que acabam com uma visão limitada sobre a relação entre língua e sociedade e sobre Políticas Linguísticas a serem adotadas.

É fato que o acesso à chamada "variante padrão escolarizada" é importante para o aluno, visto que é ela que possibilitará sua inclusão no mundo do trabalho, no prosseguimento dos estudos, na comunicação através dos meios formais e na inclusão social. Contudo, focar apenas nessa variante limita os alunos, muitas vezes ignorando e mesmo estigmatizando as variantes que eles trazem com eles; variantes que eles aprenderam e que usam em suas casas, no dia a dia com suas famílias, e que de fato os constituem. 
Outro aspecto que percebemos em nossa discussão é sobre o ensino da gramática. Verificamos nos dizeres dos participantes da pesquisa, que muitos professores trabalham com a gramática de forma compartimentada e descontextualizada. De acordo com suas falas, vemos grande preocupação com relação ao ensino tradicional, quando se dá muita ênfase apenas ao ensino da gramática. O que percebemos é que são utilizados métodos de ensino tradicionais, com exercícios de memorização e repetição que pouco proporcionam o ganho de conhecimento pelo aluno. Dessa forma, é preciso destacar que o ensino da gramática é importante, desde que os exercícios de produção e análise de texto sejam procedimentos dinâmicos e utilizados como conteúdos que contribuirão para a melhoria do desempenho linguístico do estudante, permitindo que ele atue sobre a língua, utilizando-se dos diversos gêneros discursivos e registros linguísticos. (Jabur, 2014, p. 39).

Outra representação que os participantes da pesquisa apresentaram sobre o ensino da língua materna no Ensino Médio é a de que ensinar é construir conhecimentos. O professor contemporâneo se vê como facilitador do processo de aprendizagem, aquele que auxilia o aluno na construção do conhecimento. O problema que se coloca é que essa representação, que aparece nos dizeres de alguns professores, nem sempre condiz com a dinâmica de sala de aula, já que ficou evidente que os exercícios de gramática, por exemplo, e a forma como essa gramática vai ser "apresentada" são definidos pelo professor, sem a participação dos alunos. É sempre o professor quem define, apresenta, explica e cobra os pontos a serem ensinados. É um processo quase unilateral.

Sobre os possíveis impactos dessas representações que podem ser percebidos no contexto de ensino de Língua Portuguesa pudemos notar o papel fundamental do professor como profissional que poderá, dependendo da Política Linguística em jogo, criar condições para que a Língua Portuguesa seja apresentada aos alunos de forma integral, que o aluno possa conhecer, além da variante culta da língua, outras variantes, também legítimas, e o papel que elas exercem em nossa sociedade.

É preciso reconhecer que, através do ensino da norma culta da língua, o aluno tem a possibilidade de interpretar melhor o texto e usar a língua com maior criticidade e eficiência, no que concerne à produção textual. Mas a forma como essas regras gramaticais e sintáticas [que geralmente são o foco do ensino nas aulas de Língua Portuguesa] são abordadas nas aulas pode fazer toda a diferença para um ensino mais completo e eficaz. Este é um dos pontos evidenciados nos dizeres de alguns professores: o reconhecimento de um ensino mais voltado para nomenclatura gramatical, de forma descontextualizada. Segundo os dizeres dos professores participantes da pesquisa, esta é uma característica que está presente nas escolas em que atuam. Contudo, ainda através de seus dizeres, há um despertar do professor para um ensino mais amplo sobre linguagem, que proporciona ao aluno "abrir os olhos" para uma consciência crítica de interação social.

O que pode ser percebido em relação à Política Linguística adotada para o ensino de Língua Portuguesa no âmbito das escolas regulares, no contexto investigado, é que, de acordo com as discussões apresentadas, as Políticas Linguísticas norteiam o ensino de uma única variante da Língua Portuguesa, e influenciam diretamente na escolha de metodologias e de conteúdos a serem ministrados em sala de aula. Segundo as falas de alguns professores, participantes da pesquisa, as Políticas Linguísticas ainda não funcionam bem, porque a formação de professores, nesta área do conhecimento, ainda é falha. A nosso ver, o tema Políticas Linguísticas é um tema novo para alguns professores e ainda é pouco discutido em âmbito nacional, uma vez que quase não existe a disciplina de Políticas Linguísticas nos cursos de graduação do Brasil e nos de pós-graduação a frequência dessa disciplina ainda é bem discreta. Pudemos perceber isto através de conversa informal com os professores participantes da pesquisa que relataram seus medos em falar sobre este assunto.

Considerando os resultados da pesquisa, pudemos averiguar que o problema proposto foi respondido, visto que através das concepções de professores pudemos perceber que há forte influência da Política Linguística no ensino de língua materna. Todavia, percebemos que ainda há falhas na formação docente, com relação à Política Linguística, uma vez que alguns professores encontraram muita dificuldade em responder a algumas questões. Percebe-se que são necessárias mudanças 
para que a prática pedagógica do ensino de língua materna se torne um processo que, efetivamente, desenvolva a capacidade comunicativa do aluno, fornecendo-lhe apoio e segurança a fim de que possa apropriar-se das diversas variantes da língua, e faça uso, com desenvoltura, da variante linguística adequada para cada situação de fala.

\section{Agradecimentos}

Agradeço ao Programa de Bolsas de Qualificação para Servidores (PBQS) do Instituto Federal do Norte de Minas Gerais (IFNMG), do qual fui bolsista.

\section{Referências}

Almeida, F. J. (1993). Dimensões Comunicativas no Ensino de Línguas. (1. ed). Pontes.

André, M. E. D. A. (1983). Texto, contexto e significado: algumas questões na análise de dados qualitativos. Cadernos de Pesquisa, (45), 66-71. http://publicacoes.fcc.org.br/index.php/cp/article/view/1491/1485

Brasil. (1996). Lei de Diretrizes e Bases da Educação Nacional. Presidência da República. Lei nº 9.394 , de 20 de dezembro de 1996. http://www.planalto.gov.br/ccivil_03/leis/19394.htm

Brasil. (2000). Parâmetros Curriculares Nacionais: Língua Portuguesa. Ministério da Educação.http://portal.mec.gov.br/seb/arquivos/pdf/14_24.pdf

Brasil. (2017). Base Nacional Comum Curricular. Ministério da Educação. http://basenacionalcomum.mec.gov.br

Brasil. (2017). Lei de Diretrizes e Bases da Educação Nacional. Presidência da República. Lei $\mathrm{n}^{\circ} 13.415$, de 16 de fevereiro de 2017. http://www.planalto.gov.br/ccivil_03/_ato2015-2018/2017/lei/113415.htm

Calvet, L.-J. (2002). Sociolinguística: uma introdução crítica. Parábola.

Calvet, L.-J. (2007). As políticas linguísticas. Parábola.

Correa, D. A. (2009). Política linguística e ensino de língua. Calidoscópio, 7(1). 72-78.

http://revistas.unisinos.br/index.php/calidoscopio/article/view/4856/2114.

Correa, D. A. (2010). Política linguística e o curso de licenciatura em letras: um estudo inicial sobre o PEC-G. Linguagem em foco, 2 (3). 39-52. https://revistas.uece.br/index.php/linguagememfoco/article/view/1709/1472

Correa, D. A. (2014). Práticas linguísticas e ensino de língua: variáveis políticas. In A. D. Correa (Org.), Política linguística e ensino de língua. (1, 1., 21-37) Pontes.

http://revistas.unisinos.br/index.php/calidoscopio/issue/archive

Dias, D. R. B. S. \& Silva, D. M. (2020). Reflexões sobre o ensino de gramática contextualizada. Facit Business and Technology Journal, 1(19.ed). 119-134 http://revistas.faculdadefacit.edu.br/index.php/JNT/article/view/714/519

Fiad, R. S. \& Carbonari, M. do C. (1985). Teoria e prática do ensino de língua materna. Cadernos CEDES. https://www.cedes.unicamp.br/publicacoes/11

Fiorin, J. L. (2002). Considerações em Torno do Projeto de Lei n 1676/99. In: C. A. Faraco. (org.). Estrangeirismos: guerras em torno da língua. Parábola.

Freud, S. (1980). Psicopatologia da vida cotidiana. Editora Imago.

Guarda, T. A. (2017). Política linguística e o ensino de língua portuguesa no contexto do ensino médio brasileiro [Dissertação de Mestrado, Universidade Federal de Uberlândia]. Repositório Institucional - Universidade Federal de Uberlândia. https://repositorio.ufu.br/handle/123456789/21485

Jabur, E. N. A. (2014). Ensino da língua na escola pública. In A. D. Correa (Org.), Política linguística e ensino de língua. Pontes.

Lacan, J. (1988). Função e campo da fala e da linguagem em psicanálise. Jorge Zahar.

Lima, M. C. (2004). Monografia: a engenharia da produção acadêmica. (1. ed). Saraiva.

Machado, K. K. F., Folmer, V. \& Balk, R. S. (2021). Uma prática de leitura contemporânea para adolescentes e jovens. Research, Society and Development, $10(2)$.

https://rsdjournal.org/index.php/rsd/article/view/12348

Minayo, M. C. S. (1994). Pesquisa Social: teoria, método e criatividade. Vozes.

Moita, L. L. P. (1996). Oficina de linguística aplicada: a natureza social e educacional dos processos de ensino/aprendizagem de línguas. (1. ed). Mercado das letras. 
Research, Society and Development, v. 10, n. 17, e208101724457, 2021 (CC BY 4.0) | ISSN 2525-3409 | DOI: http://dx.doi.org/10.33448/rsd-v10i17.24457

Mór, W. M. (2013). As políticas de ensino de línguas e o projeto de letramentos. In: C. Nicolaides. et al. (Orgs.). Política e Políticas Linguísticas. 1(1. ed). 219-235. Pontes.

Possenti, S. (1996). Por que (não) ensinar gramática na escola. (2. ed). Mercado de Letras.

Rajagopalan, K. (2003). Por uma linguística crítica. Linguagem, identidade e a questão ética. Parábola.

Rajagopalan, K. (2013). Política Linguística, do que é que se trata, afinal? In C. Nicolaides. et al (Orgs). Política e Políticas Linguísticas. 19-42. Pontes.

Rajagopalan, K. (2014).O professor de línguas e a suma importância do seu entrosamento na política linguística do seu país. In A. D. Correa. (Org.). Política linguística e ensino de língua. 73-82. Pontes.

Travaglia, L. C. (1998). Gramática e interação: uma proposta para o ensino da gramática no $1^{\circ}$ e $2^{\circ}$ graus. (4. ed). Cortez. 